\title{
Phytoprotection
}

\section{Impact de certains organismes pathogènes nouveaux ou en ré-émergence sur les productions horticoles au Québec}

\section{Lacroix}

Volume 80, numéro 2, 1999

URI : https://id.erudit.org/iderudit/706186ar

DOI : https://doi.org/10.7202/706186ar

Aller au sommaire du numéro

Éditeur(s)

Société de protection des plantes du Québec (SPPQ)l

ISSN

0031-9511 (imprimé)

1710-1603 (numérique)

Découvrir la revue

Citer cet article

Lacroix, M. (1999). Impact de certains organismes pathogènes nouveaux ou en ré-émergence sur les productions horticoles au Québec. Phytoprotection, 80(2), 115-120. https://doi.org/10.7202/706186ar d'utilisation que vous pouvez consulter en ligne. 


\title{
Impact de certains organismes pathogènes nouveaux ou en ré-émergence sur les productions horticoles au Québec
}

\author{
Michel Lacroix \\ Laboratoire de diagnostic en phytoprotection, Direction des services technologiques, \\ Ministère de I'Agriculture, des Pêcheries et de l'Alimentation du Québec, Complexe \\ scientifique, 2700, rue Einstein, Sainte-Foy (Québec) Canada G1P 3W8
}

\section{PHYTOPROTECTION 80: 115-120}

En 1986, le ministère de l'Agriculture, des Pêcheries et de I'Alimentation du Québec a mis en place le Laboratoire de diagnostic en phytoprotection. Depuis ce temps, quelque 25000 échantillons ont été examinés par le personnel de la section phytopathologie. Les plantes reçues se répartissent parmi les diverses productions végétales du Québec de la façon suivante : plantes maraîchères $(45 \%)$, plantes ornementales (24\%), petits fruits $(19 \%)$, arbres et arbustes d'ornement $(14 \%)$, arbres fruitiers $(2 \%)$, céréales et maïs ( $2 \%)$, plantes industrielles $(2 \%)$, plantes fourragères $(1 \%)$ et fines herbes ( $1 \%)$.

Les problèmes phytosanitaires identifiés sur les plantes cultivées au Québec se regroupent sous deux grandes catégories : maladies parasitaires $(67 \%)$ et problèmes non parasitaires (33\%). Les organismes phytopathogènes sont répartis selon les proportions suivantes: champignons $(47 \%)$, bactéries $(10 \%)$, virus $(7 \%)$, nématodes $(2 \%)$ et phytoplasmes (1\%). Quant aux problèmes non parasitaires, ils sont associés aux paramètres suivants: pratiques culturales (gestion de l'eau, des fertilisants) $(15 \%)$, facteurs climatiques (température, pluviométrie, ensoleillement)
(13\%), phytotoxicité des pesticides $(4 \%)$ et désordre génétique (1\%).

En relation avec le concept de ravageurs nouveaux et en ré-émergence, les informations recueillies au Laboratoire de diagnostic en phytoprotection peuvent être analysées sous des angles différents :

- citations des premières mentions pour le Québec de certains organismes phytopathogènes;

- énumération des plantes-hôtes pour des organismes phytopathogènes fréquemment identifiés;

- description de problèmes non parasitaires régulièrement diagnostiqués sur les plantes cultivées.

Cependant, depuis la mise en place du Laboratoire de diagnostic en phytoprotection, certains organismes phytopathogènes ont un impact majeur sur des productions horticoles, en engendrant des pertes importantes au sein de plusieurs entreprises agricoles. D'autres maladies parasitaires, bien que non présentes sur l'ensemble du territoire québécois, ont également des conséquences considérables pour certaines exploitations agricoles.

Note du rédacteur : le texte ci-dessus est présenté tel que soumis / Editor's note : the above text is presented as submitted. 
En considérant l'incidence économique sur les productions horticoles au Québec, une sélection d'organismes pathogènes nouveaux ou en ré-émergence sont présentés en les regroupant par catégorie, à savoir les virus, les bactéries, les champignons et les nématodes.

\section{VIRUS}

- Impatiens necrotic spot virus (INSV) et Tomato spotted wilt virus (TSWV)

Hôtes: plantes maraîchères et ornementales

Jusqu'en 1992, la littérature faisait mention du TSWV-L (souche laitue) et du TSWV-I (souche impatiens). En se basant sur des caractéristiques sérologiques, le TSWV-I est alors considéré comme un virus distinct et a reçu l'appellation de INSV. En se référant aux tests réalisés au Laboratoire de diagnostic en phytoprotection, le INSV est détecté chez les plantes ornementales et le TSWV chez les plantes maraîchères.

Au-delà de 300 espèces végétales peuvent être infectées par le INSV et le TSWV. Au Québec, le INSV est de loin le virus le plus important chez les plantes ornementales. Cette maladie virale est présente d'une année à l'autre, sans exception. Outre l'impatiens et l'impatiens de Nouvelle-Guinée, cultures particulièrement sensibles au INSV, ce virus a été détecté entre autres dans les cultures suivantes: bégonia, basilic, chrysanthème, cyclamen, dieffenbachia, exacum, gloxinia, hoya, kalanchoe, muflier, primevère, salvia, tagète, spathiphyllum et zinnia. Quant au TSWV, il a été diagnostiqué principalement chez la tomate.

II est difficile de dégager un symptôme commun à toutes les espèces végétales infectées par le INSV ou le TSWV. Les expressions les plus habituelles de la maladie sont: rabougrissement et nanisme, anneaux nécrotiques, taches concentriques, brûlures des nervures, lésions sur la tige et déformation des fleurs. Contrairement à plusieurs maladies virales qui affectent un nombre restreint de plantes dans une culture, le
INSV et le TSWV peuvent causer des pertes considérables.

La dissémination du INSV et du TSWV est assurée par le thrips des petits fruits (Frankliniella occidentalis) et par le bouturage de plants-mères infectés.

\section{- Potato virus X (PVX)}

Hôte : tomate de serre

Au Québec, cette maladie a été diagnostiquée pour la première fois chez la tomate de serre en 1993. Bien que le PVX puisse affecter un nombre important de plants de tomate dans une serre, il demeure que les pertes engendrées par cette maladie virale ne sont généralement pas considérables. Cependant, les symptômes ont une apparence particulièrement impressionnante. Localisés sur les feuilles, ils se définissent par une mosaïque grave constituée de nombreuses lésions angulaires jaunes, vert pâle et vert foncé se chevauchant les unes sur les autres.

\section{BACTÉRIES}

- Clavibacter michiganensis subsp. michiganensis (chancre bactérien)

Hôtes : tomate de champ et de serre

Les symptômes induits par cette maladie bactérienne sont fort différents chez la tomate de champ et de serre :

Tomate de champ : Le symptôme le plus caractéristique demeure la présence d'une brûlure brun foncé répartie sur une grande partie de la marge des folioles affectées. Cette brûlure peut être bordée par un jaunissement. Sur les fruits, il y a présence de lésions circulaires ( $2 \mathrm{~mm}$ de diamètre), protubérantes ayant une couleur blanche avec un centre brun.

Tomate de serre: L'affaissement et le dessèchement des tissus entre les nervures des folioles est un symptôme typique. Au début, les tissus sont kaki et leur aspect est humide mais rapidement ils deviennent beiges et secs. Un flétrissement des plants peut être observé. Ces symptômes sont la conséquence $d^{\prime}$ une infection du système vasculaire laquelle se manifeste par un 
brunissement des vaisseaux, particulièrement apparent dans la région des nœuds de la tige. Les fruits ne montrent aucune lésion.

Pour les producteurs de tomate de serre, le chancre bactérien représente la maladie la plus redoutable. Son développement peut être fulgurant et son éradication est impossible, étant donné l'absence de méthodes de lutte curatives une fois l'infection établie. Souvent des centaines de plantes doivent être éliminées à chaque semaine suite à l'apparition du chancre bactérien dans une serre.

Jusqu'en 1991, cette maladie demeurait insoupçonnée dans les cultures de tomate de serre. Depuis ce temps, le chancre bactérien est diagnostiqué à chaque année au sein d'entreprises serricoles. Pour la tomate de champ, une recrudescence de ce problème bactérien est observée au Québec depuis 3 ans.

- Erwinia amylovora (brûlure bactérienne)

Hôte : framboisier

La brûlure bactérienne est reconnue pour causer des dommages chez le pommier. Le framboisier, particulièrement le cultivar Boyne, peut également être gravement affecté par l'Erwinia amylovora. Les symptômes sont typiques. Ils se caractérisent par un noircissement affectant les nervures ou tout le limbe des feuilles terminales. Ces dernières demeurent souples. Le noircissement parvient à gagner la tige, laquelle vient à se recouvrir d'un exsudat bactérien gommeux. L'extrémité de la tige peut se recourber et prendre la forme d'une canne. Les fruits deviennent également noirs et se dessèchent. Cette maladie bactérienne semble de plus en plus présente dans les framboisières québécoises.

- Xanthomonas campestris pv. armoraciae (tache bactérienne)

Hôtes : crucifères

Cette maladie a été diagnostiquée sur des transplants de crucifères produits en serre, à savoir le brocoli, le chou et le chou-fleur. Au Québec, la première mention de la tache bactérienne date du milieu des années 1990. Depuis ce temps, elle fait son apparition à chaque année. La préoccupation des producteurs concerne la distinction entre la tache bactérienne et la nervation noire (Xanthomonas campestris pv. campestris). La nervation noire représente une menace plus sérieuse puisque la bactérie cause une infection systémique en migrant dans le système vasculaire, d'où les dommages plus importants à la culture. Quant au Xanthomonas campestris pv. armoraciae, cet agent pathogène induit une infection locale qui se traduit sur les feuilles par le développement de taches circulaires (diamètre 1 à $2 \mathrm{~mm}$ ), beiges ayant une marge foncée habituellement noire. La tache peut être entourée d'un halo jaune ou aqueux. Sur les cotylédons, une ponctuation noire peut apparaître.

- Xanthomonas campestris pv. pelargonii (tache bactérienne)

Hôte : géranium (Pelargonium)

Cette maladie bien que sporadique peut causer des dommages très importants en considérant qu'il se produit annuellement plus de 6 millions de plants de géraniums au Québec. La dernière épidémie du Xanthomonas campestris pv. pelargonii remonte à 1993. À chaque année, cette maladie exige des producteurs un suivi rigoureux de leurs boutures. Les symptômes sont variables. Ils peuvent se limiter à des taches et brûlures foliaires mais puisque la bactérie est systémique; des jaunissements et du dépérissement peuvent être observés.

- Xanthomonas campestris pv. vitians (nécrose marginale)

Hôte : laitue

Au Québec, la nécrose marginale a été identifiée pour la première fois en 1994. Depuis ce temps, cette maladie est présente dans les champs de laitue localisés dans le sud de Montréal. Certaines années des pertes importantes ont été rapportées suite à des infections par le Xanthomonas campestris pv. vitians. 


\section{CHAMPIGNONS}

Puisque plusieurs champignons phytopathogènes nouveaux ou en ré-émergence affectent la tomate de serre, les maladies fongiques sont réparties en deux groupes en considérant dans un premier temps la tomate de serre et par la suite les autres cultures.

\section{Tomate de serre}

\section{- Acremonium strictum et Plectospo- rium tabacinum (chancre sec)}

Cette maladie s'apparente à certains égards à la moisissure grise causée par le Botrytis cinerea. Cependant, les caractéristiques associées au chancre sec sont les suivantes : lésions beiges débutant à un nœud situé à la base de la tige, affaissement de la lésion nodale et développement $d$ 'un chancre beige unidirectionnel soit vers la base de la tige, brunissement et affaissement de la moelle, système vasculaire sain et absence d'un sporulation visible à l'œil nu. Le pouvoir pathogène de l'Acremonium strictum et du Plectosporium tabacinum a été établi en 1996 (travaux de recherche réalisés par Horti-Protection). Cette maladie est particulièrement importante dans les entreprises serricoles produisant sur une période continue de 12 mois.

\section{- Erysiphe orontii (blanc)}

À l'automne 1993, un premier échantillon de tomate de serre provenant de la région de Saint-Hyacinthe est diagnostiqué positif pour la présence du blanc. Par la suite, des échantillons des régions de Québec et du Saguenay-LacSaint-Jean révèlent également la présence de cette maladie. Cette dernière se manifeste par la présence de taches blanches d'aspect poudreux sur la face supérieure des folioles. Seul le stade conidien du champignon est observé. Le Dr J.A. Parmelee du Service national d'identification des champignons d'Agriculture et Agroalimentaire Canada précise alors que le champignon responsable est I'Erysiphe orontii. II s'agissait donc de la première mention canadienne de cet organisme pathogène chez la tomate. Depuis ce temps, le blanc est devenu une maladie observée à chaque année dans les productions de tomate de serre.

\section{- Humicola fuscoatra var. fuscoatra}

En 1992, les résultats d'une recherche réalisée au Pays-Bas ont permis de démontrer l'implication du Humicola fuscoatra var. fuscoatra dans le développement de racines ayant un aspect liégeux (" corky root"). La présence d'aleuroconidies du Humicola est régulièrement notée dans les racines de plants de tomate (reçus au Laboratoire de diagnostic en phytoprotection) présentant un renflement, un brunissement et une pourriture des tissus corticaux. Cependant, des études supplémentaires seraient nécessaires afin d'élucider l'impact réel de ce nouveau champignon pathogène.

\section{- Phytophthora infestans (mildiou)}

Ayant fait son apparition en Amérique du Nord en 1843, le mildiou ne peut être considéré comme une maladie nouvelle, mais il s'agit certainement d'un problème en ré-émergence. Au début des années 1990, l'introduction en provenance du Mexique de nouvelles lignées plus virulentes du Phytophthora infestans a eu un impact majeur. En effet, en 1994 une épidémie importante du mildiou a détruit entièrement des champs de pomme de terre. Ces lignées récemment introduites ont également eu une répercussion chez la tomate de serre. En 1994 et en 1998, le Phytophthora infestans a causé des dommages importants à cette culture, pouvant aller jusqu'à la destruction complète. Chez la tomate de serre, la progression de la maladie peut être impressionnante. Suite à l'infection, le mildiou peut anéantir une culture en 3 ou 4 jours si les conditions lui sont favorables. Au Québec, le mildiou fait habituellement son apparition dans les cultures de tomate à la fin du mois d'août ou au début du mois de septembre. 
- Pythium spp. (pourridié pythien)

Au Québec, les Pythium n'étaient pas considérés comme des organismes pathogènes d'importance pour la culture de la tomate de serre. Cependant, l'avènement de la culture en laine de roche et sur film nutritif (NFT) a offert un environnement particulièrement favorable au Pythium, puisque ce champignon est bien adapté pour croître dans les milieux aqueux et que ces derniers contiennent peu d'organismes pouvant offrir une compétition au Pythium. Le pourridié pythien est désormais une maladie régulièrement identifiée dans les racines de la tomate de serre présentant un brunissement et une pourriture. Tout stress d'oxygénation, de salinité et de température sera alors des plus favorables pour une infection par le Pythium. Au Québec, les Pythium du groupe $\mathrm{F}$, le Pythium ultimum et à de très rares occasions, le Pythium aphanidermatum ont été identifiés dans des plants de tomate de serre.

\section{- Verticillium albo-atrum (flétrissement verticillien)}

Bien que pouvant être observée à chaque année chez la tomate de serre, cette maladie fongique affecte généralement quelques plantes seulement. Cependant, une nouvelle dynamique s'est établie à I'hiver 1999. Des dommages considérables ont été causés par le flétrissement verticillien. Des centaines de plants de tomate devaient être éliminés des serres à chaque semaine suite à l'infection par Verticillium albo-atrum. Outre le jaunissement et le flétrissement foliaires associés à la coloration beige du système vasculaire, des chancres graves bruns à grisâtres, ouverts et ayant un aspect humide pouvaient apparaître sur les tiges. Ces chancres sont inhabituels chez la tomate de serre infectée par le Verticillium. II est donc des plus pertinents de suivre l'évolution de cette maladie au Québec.

\section{Autres cultures}

- Phytophthora capsici (pourriture du fruit)
Hôtes : poivron, melon d'eau, cornichon

Au Québec, le Phytophthora capsici a été identifié pour la première fois en 1995 dans une culture de poivrons. Les symptômes observés sur les plants de poivron se définissent ainsi : dépérissement du feuillage, chancres brun foncé à noirs sur les tiges, brunissement interne au collet, détérioration du système racinaire ainsi qu'une pourriture et momification des fruits. Chez les cucurbitacées, les feuilles ne sont pas affectées mais les fruits présentent en premier des zones vert sombre sur lesquelles un mycélium blanc d'aspect humide se développe. Jusqu'en 1997, seulement des cas isolés ont été rapportés mais au cours de l'année de production 1998, le nombre de pertes et leur gravité se sont accrus de façon significative.

- Phytophthora spp. (pourridié des racines)

Hôte : framboisier

Insoupçonnée jusqu'en 1987, cette maladie fongique a eu un impact majeur dans les framboisières au Québec. Les pertes encourues par ce champignon furent considérables. Le pourridié des racines demeure toujours d'actualité. II a engendré des modifications importantes dans les pratiques culturales afin de minimiser les pertes. II a également été au centre de nombreux travaux de recherche.

\section{- Rhizoctonia carotae (rhizoctone)}

Hôte : carotte

Possédant peu de données sur cette maladie, il apparaît que le rhizoctone soit plus important depuis 2 ans dans les carottes entreposées.

\section{NÉMATODES}

\section{- Ditylenchus dipsaci}

Hôtes : ail et phlox subulé

Chez I'ail, le Ditylenchus a été diagnostiqué dans les bulbes présentant des pourritures. Chez le phlox subulé, le nématode infecte la tige. L'épiderme 
des tiges s'épaissit, se gonfle et pourrit ce qui entraîne un jaunissement, un brunissement et un dessèchement $d u$ feuillage.

\section{- Longidorus spp.}

Hôtes : fraisier et framboisier

Ce nématode a été identifié pour la première fois au Laboratoire de diagnostic en phytoprotection en 1998. Les symptômes associés à cet organisme pathogène consistaient en des renflements de l'extrémité des racines et en une détérioration de celles-ci.

\section{- Xiphinema spp.}

Hôte : framboisier

En 1998, des framboisiers présentant des fruits avec peu de drupéoles, de grosseurs très variables et avec une faible cohésion entre les drupéoles, ont été reçus au Laboratoire de diagnostic en phytoprotection. Un test ELISA a permis de révéler la présence du Tomato ringspot virus (ToRSV) dans les échantillons. Ce virus est reconnu pour causer la chapelure (" crumbly fruit") chez le framboisier. Suite à une extraction des nématodes dans le sol, du Xiphinema a été détecté, organisme vecteur du ToRSV. Pour le Laboratoire de diagnostic en phytoprotection, il s'agissait de la première mention du Xiphinema. Bien que cette maladie demeure rare, les pertes encourues dans les framboisières ayant la présence du Xiphinema et du ToRSV ont été considérables. 